\title{
Compact Ultra Wideband (UWB) Elliptical Monopole with Potentially Reconfigurable Band Rejection Characteristic
}

\author{
Symeon Nikolaou ${ }^{1}$, Arnaud Amadjikpe ${ }^{1}$, John Papapolymerou ${ }^{1}$, and Manos M. Tentzeris ${ }^{1}$ \\ (1) School of Electrical and Computer Engineering \\ Georgia Institute of Technology \\ Atlanta, GA 30332-0250, U.S.A. \\ simos@ece.gatech.edu
}

\begin{abstract}
A CPW-fed compact elliptical monopole UWB antenna is introduced with potentially reconfigurable band rejection characteristic at the band used for wireless LAN applications. The antenna is fabricated on thin $(100 \mu \mathrm{m})$ liquid crystal polymer (LCP) and the band notch is caused by the presence of a two resonating inverted $\mathrm{L}$-shaped stubs that are connected to the elliptical radiator. The frequency notch can be potentially reconfigurable with the use of switches that would connect and disconnect the stubs on the elliptical radiator. Surface currents' distribution and a simple transmission line model are used to interpret the effect of the two stubs on the radiation mechanism. The presence of the stubs does not alter the radiation patterns behavior which is almost identical to the behavior of a design without any stubs with the exemption of the gain in the frequency notch band, which is maintained negative.
\end{abstract}

Keywords: antenna, reconfigurable band rejection, ultra wideband, 1-shaped stubs

\section{INTRODUCTION}

When FCC released the Ultra Wide Band protocol that covers the frequency range from $3.1-10.6 \mathrm{GHz}$ in 2002 [1], the interference with other applications was partly compensated with the significantly low emitted power from UWB radios (EIRP $-41.3 \mathrm{dBm} / \mathrm{MHz}$ ). However, while the operation of UWB radios is almost "invisible" for applications using the HIPERLAN/2 bands $(5.15-5.35 \mathrm{GHz}, 5.470-5.725 \mathrm{GHz})$ and the IEEE 802.11a bands (5.15-535 GHz, 5.725-5.825 GHz), their operation, can degrade the performance of UWB communication systems. Therefore there is a need for UWB antennas with band rejection characteristics in the aforementioned frequency bands. Various approaches have been proposed from time to time in order to design compact antennas with the desired features. The use of a tuning stub has been introduced in [2], parasitic patches has been used in [3], while short stubs on a slot line have been proposed in [4]. The most popular solution has been the introduction of a U-shaped slot in a microstrip fed monopole which has been used by many researchers [5-7]. The introduction of a U-shaped slot in a microstrip fed monopole has been the most popular solution and used by many researchers. In most of those these cases, the achievement of a potentially reconfigurable design is not an easy task because of the geometry of the introduced resonating element.

In this paper, a CPW-fed elliptical monopole is fabricated on ultra thin $(100 \mu \mathrm{m})$ LCP (liquid crystal polymer) material, with potentially reconfigurable band-notch characteristics. The fabricated prototype which uses two inverted L-shaped, approximately $\lambda / 4$ long (at $5.5 \mathrm{GHz}$ ) open stubs is analyzed and compared with the elliptical monopole with the stubs disconnected and the classical elliptical monopole with no stubs. The electrically connected open stubs cause the frequency notch in the return loss, while they do not degrade the radiation pattern behavior which remains consistently omni-directional. With the use of either PIN diodes or MEMS switches the stubs can be electrically connected or disconnected dynamically, resulting in a reconfigurable frequency notch.

\section{ANTENNA DESIGN AND FABRICATION}

\section{A. Fabrication}

The proposed antennas are presented in Fig. 1. The prototype on the left is the antenna with the disconnected stubs and the one on the right is the classical elliptical monopole. They are fabricated on low loss $(\tan \delta=0.002)$, low dielectric constant $\left(\varepsilon_{\mathrm{r}}=3\right), \mathrm{LCP}$ with a $18 \mu \mathrm{m}$ thick copper layer. The $\mathrm{CPW}$-fed elliptical monopoles are fabricated on a very thin, $100 \mu \mathrm{m}$ thick substrate. The proposed antenna is fabricated on conformal LCP material. The prototype can be easily fabricated using engineered CTE.

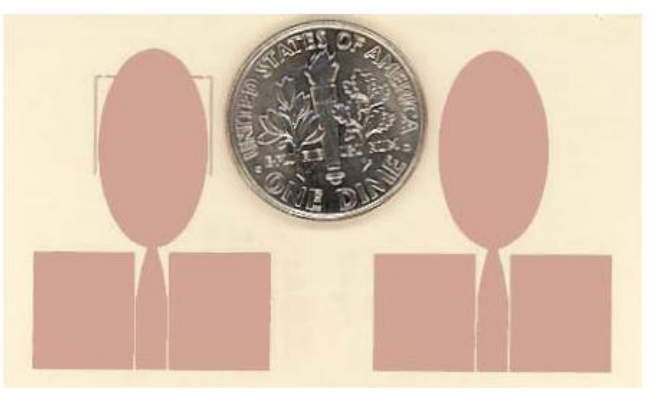

Figure 1. Fabricated Prototypes 


\section{B. Schematic discussion}

Antenna topologies are presented in Fig. 2. Table I summarizes the dimensions of the different structures. Ansoft HFSS software [9] was used for the design and optimization of the prototype.

The proposed antenna is fed by a CPW line with an inner conductor width, W, of $2.75 \mathrm{~mm}$ and a gap of $0.18 \mathrm{~mm}$ between the ground and the inner conductor. At a distance $\mathrm{H}=6.38 \mathrm{~mm}$ from the board edge, the inner conductor is linearly tapered until its width reaches $0.84 \mathrm{~mm}$ to improve the matching between the transmission line and the elliptical radiator. The major and minor axes of the elliptical monopole are equal to $17.60 \mathrm{~mm}(\mathrm{~L} 1)$ and $9.68 \mathrm{~mm}$ (L2) respectively. For compact UWB antennas the design and optimization of the ground size is critical for the overall antenna performance. The ground patches used for this structure have dimensions 10.38 $\mathrm{mm}$ by $8.94 \mathrm{~mm}$ that result in a very compact design. The frequency notch observed in the return loss measurements is caused from the symmetrically placed inverted L-shaped stubs. The stubs are placed at a distance $O, 2.40 \mathrm{~mm}$ from the top end of the elliptical radiator. They consist of two orthogonally connected segments, with lengths $\mathrm{Ws}_{\mathrm{s}}, 1.88 \mathrm{~mm}$ and $\mathrm{Ls}, 8.80$ $\mathrm{mm}$, respectively. The total length of each stub is approximately $\lambda / 4$ at $5.5 \mathrm{GHz}$ and the stub width is only 0.2 $\mathrm{mm}$. For the prototype with the disconnected stubs, a $0.2 \mathrm{~mm}$ long gap is added on each stub at a distance of $0.98 \mathrm{~mm}$ from the elliptical radiator. The gap represents the potentially integrated switch at the "OFF" position. The overall board dimensions of the fabricated prototype are $32 \mathrm{~mm}$ by 26.80 $\mathrm{mm}$ and the substrate thickness is only $100 \mu \mathrm{m}$ resulting in a compact, low profile antenna.

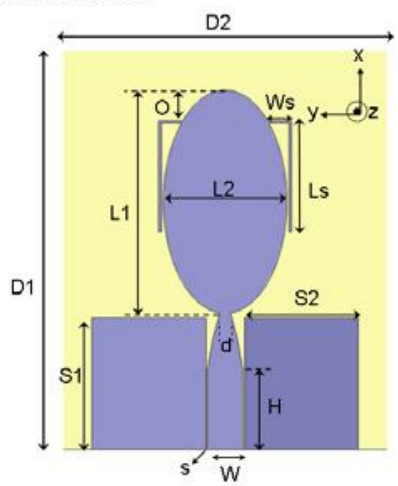

Figure 2. Antenna schematic

TABLEI. ANTENNA DIMENSIONS

\begin{tabular}{cccc}
\hline D1 & $32.00 \mathrm{~mm}$ & $\mathrm{~d}$ & $0.84 \mathrm{~mm}$ \\
D2 & $26.80 \mathrm{~mm}$ & Ws & $1.88 \mathrm{~mm}$ \\
L1 & $17.60 \mathrm{~mm}$ & Ls & $8.80 \mathrm{~mm}$ \\
L2 & $9.68 \mathrm{~mm}$ & $\mathrm{O}$ & $2.40 \mathrm{~mm}$ \\
S1 & $10.38 \mathrm{~mm}$ & $\delta$ & $2.00 \mathrm{~mm}$ \\
S2 & $8.94 \mathrm{~mm}$ & $\mathrm{R}$ & $3.85 \mathrm{~mm}$ \\
W & $2.75 \mathrm{~mm}$ & $\mathrm{Co}$ & $6.97 \mathrm{~mm}$ \\
$\mathrm{~s}$ & $0.18 \mathrm{~mm}$ & $\mathrm{H}$ & $6.38 \mathrm{~mm}$ \\
$\mathrm{D} 1$ & $32.00 \mathrm{~mm}$ & $\mathrm{~d}$ & $0.84 \mathrm{~mm}$ \\
$\mathrm{D} 2$ & $26.80 \mathrm{~mm}$ & & \\
\hline
\end{tabular}

\section{DISCUSSION OF MEASUREMENT AND SIMULATION} RESULTS

\section{A. Return loss and transmission line model}

For retum loss and radiation pattern measurements, an SMA connector was soldered onto the board. An HP8530 Network Analyzer was used to measure the return loss, which is shown in Fig. 3 with the simulated return loss. The return loss behavior for the antenna with the connected stubs is presented in Fig. 3a while the retum loss for the prototype with the disconnected stubs is shown in Fig. $3 \mathrm{~b}$. In the following figures the prototype with the connected stubs will be denoted as "Shorted Stubs" and the prototype with the disconnected stubs will be denoted as "Open Stubs". The simulated results are in good agreement with measurements. In both cases, there are two resonating frequencies around $4 \mathrm{GHz}$ and $9 \mathrm{GHz}$ respectively. Those two resonances are due to the ground size and the ellipse axes as explained in [10]. The presence of the two L-shaped stubs with a total length of approximately $\lambda / 4$ at $5.5 \mathrm{GHz}$ creates the frequency notch in the return loss. The effect of the length, Ls, on the simulated return loss is presented in Fig.4. As it can be seen from the figure, the frequency notch shifts toward lower frequencies while Ls is increased. The $\lambda / 4$ long L-shaped stubs, acting as resonating elements at $5.5 \mathrm{GHz}$, cause the frequency notch behavior observed in the return loss of the antenna. A transmission model is introduced to explain the aforementioned behavior. In the model presented in Fig. 5, the presence of the two stubs is modeled as a $\lambda / 4$ long open stub. When the stub is connected on the primary transmission line (Fig. 5a), it appears as ideal short on the transmission line (at $5.5 \mathrm{GHz}$ ) resulting in the reflection of the incident power before it gets to the radiating load. Therefore, the antenna does not radiate. When the stub is disconnected, (Fig 5b) it has no effect on the incident power which is radiated from the load. Another explanation for the radiation mechanism can be derived from Fig. 6 where the surface current distributions at $5.5 \mathrm{GHz}$ and at $8 \mathrm{GHz}$ are presented for the antenna with the connected stubs. It is obvious that in the first case (Fig. 6a) the current on the stub has an opposite direction (downwards) compared to the direction (upwards) of the current in the nearby edge of the radiator and as a result the currents cancel each other and no radiation occurs. At a different frequency where the physical length of the stubs is not $\lambda / 4$, the currents on the stubs are not aligned and hence, they do not cancel the currents on the elliptical radiator. As a result, the current distribution on the ellipse radiates.

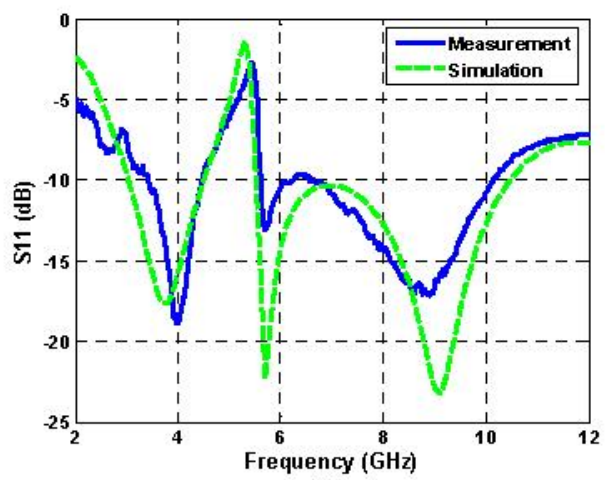

(a) 


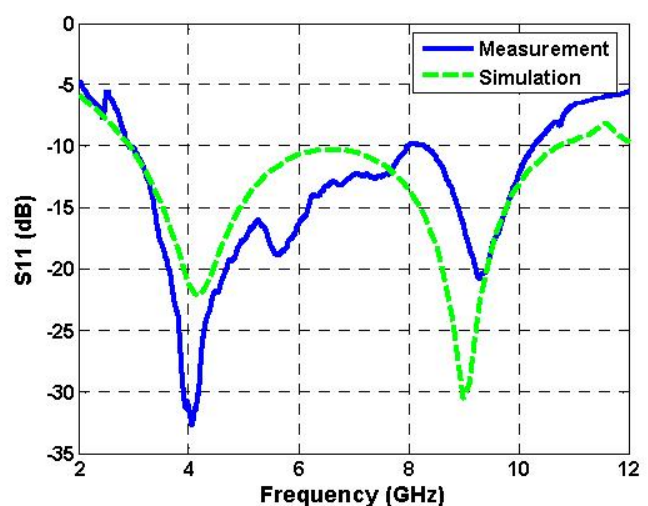

(b)

Figure 3. Measured and simulated return loss (a) Shorted stubs (b) Open stubs

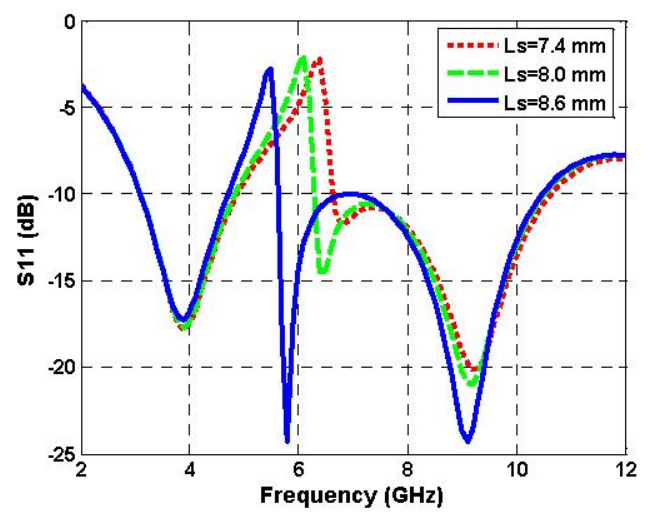

Figure 4. Parametric study of the Ls segments of the inverted L-shaped stubs.

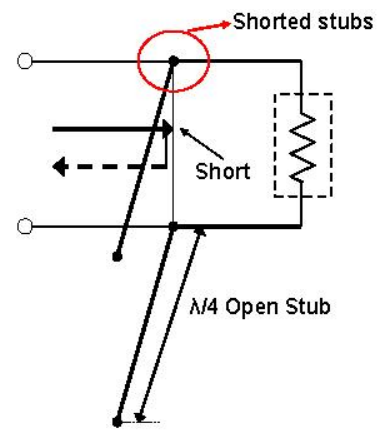

(a)

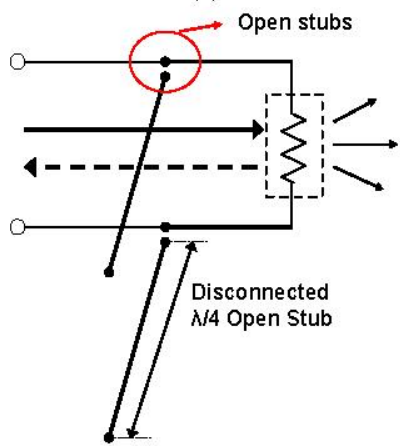

(b)

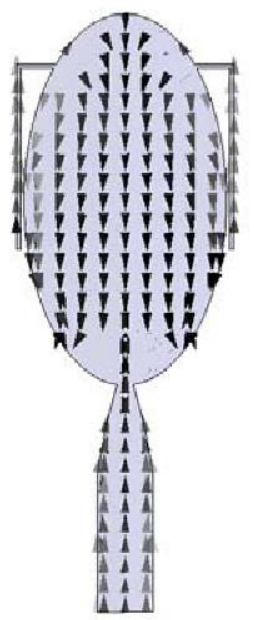

(a)

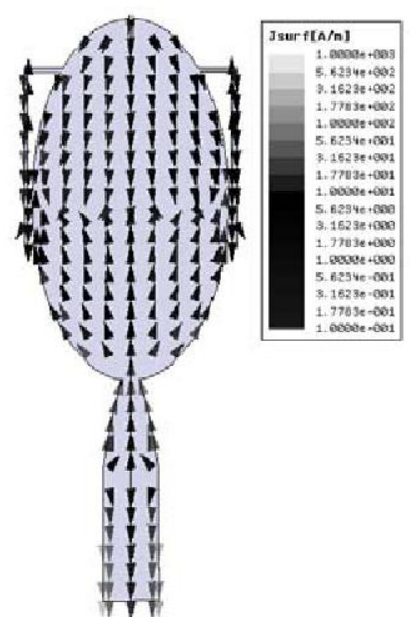

(b)
Figure 6. Surface current distribution at (a) $5.5 \mathrm{GHz}$ and (b) $8 \mathrm{GHz}$.

\section{B. Radiation patterns and gain results}

The $\mathrm{E}$ and $\mathrm{H}$ plane simulated radiation patterns at $4 \mathrm{GHz}$ and $8 \mathrm{GHz}$ are presented for the prototypes with the stubs connected, disconnected and an antenna model without any stubs which is referred to as "Reference". The selected frequencies, at $4 \mathrm{GHz}$ and $8 \mathrm{GHz}$, are representative of the entire UWB band. Measurements will be available for presentation at the conference. As can be seen in Fig. 7 and Fig. 8 where $\mathrm{E}$ and $\mathrm{H}$ plane patterns are depicted respectively, the presented radiation patterns almost coincide proving that the presence of the stubs does not affect the behavior of the radiation pattern. E plane is the $\mathrm{x}-\mathrm{z}$ plane and $\mathrm{H}$ plane is the $\mathrm{y}-\mathrm{z}$ plane with reference to the antenna orientation defined in Fig. 2. In the $\mathrm{H}$ plane the pattern has omni-directional shape for both frequencies while in the $\mathrm{E}$ plane there is a null in the feed line direction $\left(\theta=90^{\circ}\right)$ which is parallel to the $\mathrm{x}$ axis. The presence of the stubs, though, affects the gain of the antenna significantly. The total gain of the antenna in $\mathrm{dBi}$ is shown in Fig. 9. It can be seen that for the frequency notch band, the gain is negative, which is anticipated based on the return loss measurements.

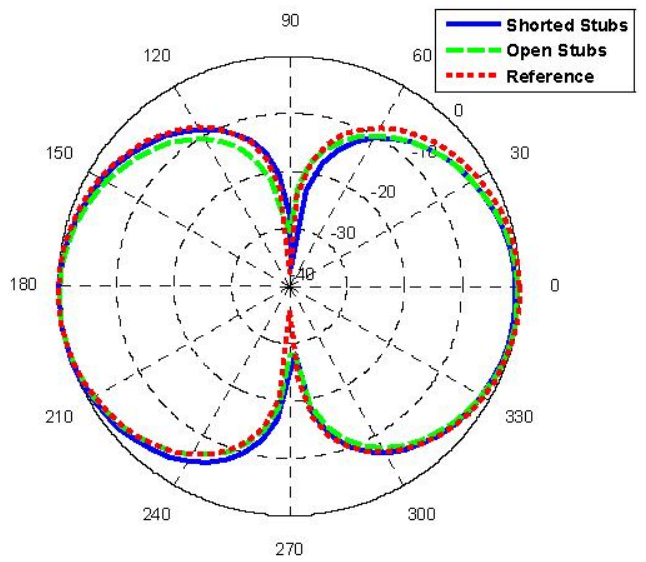

(a)

Figure 5. Transmission lime model with (a) Shorted stubs (b) Open stubs 


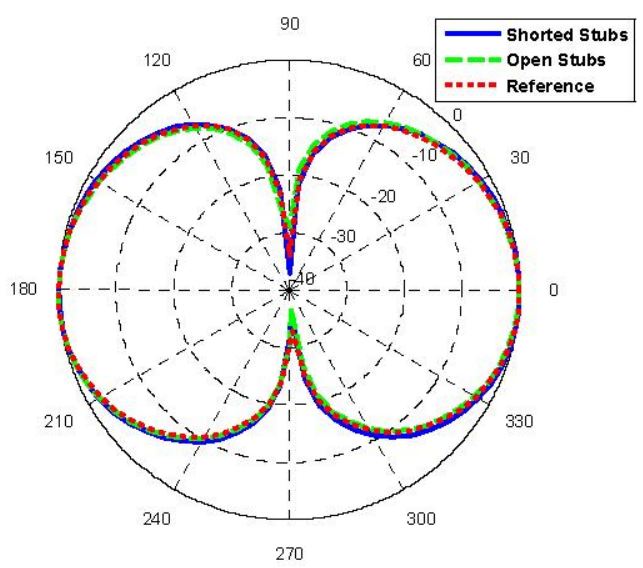

(b)

Figure 7. E plane simulations at (a) $4 \mathrm{GHz}$, and (b) $8 \mathrm{GHz}$.

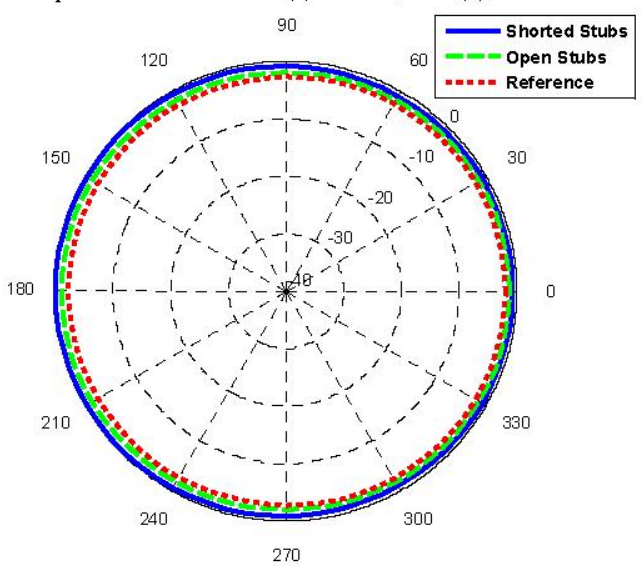

(a)

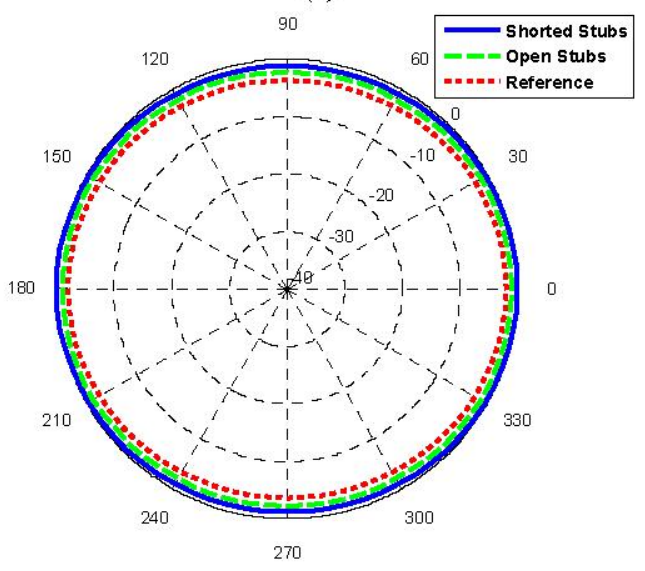

(b)

Figure 8. H plane simulations at (a) $4 \mathrm{GHz}$, and (b) $8 \mathrm{GHz}$.

\section{CONCLUSION}

A CPW-fed UWB elliptical monopole with potentially reconfigurable band rejection characteristic has been presented. The band rejection characteristic is caused by the presence of two symmetrically placed inverted L-shaped stubs with total length approximately $N 4$ at $5.5 \mathrm{GHz}$. The effect of the two stubs on the radiation mechanism was interpreted with a transmission line model and with surface current distribution analysis. The stubs can be potentially connected and disconnected from the elliptical radiator with the use of suitable switches. When the stubs are disconnected the antenna has the classical UWB performance, without any band rejection. The introduced stubs have significant impact on the return loss, while they don't affect the radiation patterns of the antenna, since the radiated modes remain unaltered. Only the gain in the rejected frequency range is degraded, as anticipated from the return loss behavior. The characteristics of a potentially reconfigurable UWB antenna make the proposed prototype a very good candidate for cognitive, UWB radios.

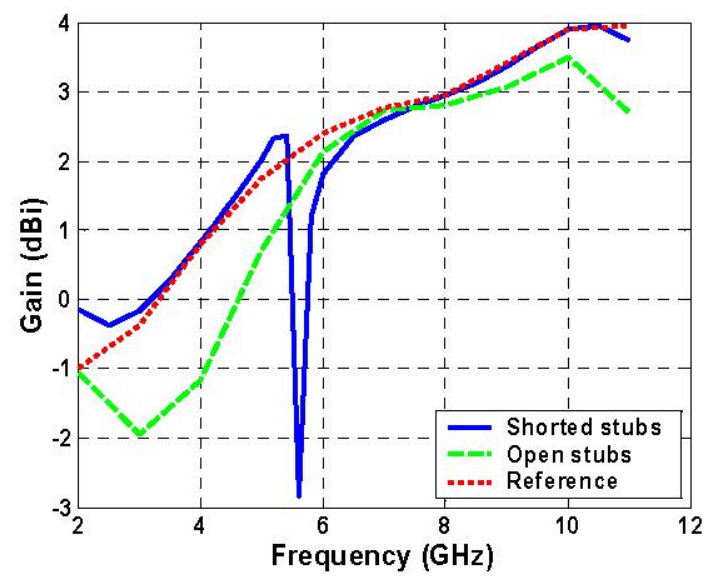

Figure 9. Gain simulations

\section{REFERENCES}

[1] Anon., FCC First Report and Order on Ultra-Wideband Technology, Feb. 2002.

[2] Y. Gao, B.-L. Ooi, A.P. Popov, "Band-notched ultra-wideband ringmonopole antenna", Microw. and Optical Tech. Lett. vol. 48, issue 1, pp. 125-126, Jan. 2006

[3] K.-H. Kim, Y.-J. Cho, S.-H. Hwang, S.-O. Park, "Band-notched UWB planar monopole antenna with two parasitic patches", Electronic Lett. vol. 41, pp. 783 - 785, Jul. 2005.

[4] I.-J. Yoon, H. Kim, K. Chang, Y. J. Yoon, Y.-H. Kim, "Ultra wideband tapered slot antenna with band-stop characteristic", IEEE APS $2004 \mathrm{vol}$. 2, pp. $1780-1783$, Jun. 2004.

[5] K. Chung, J. Kim, J. Choi , "Wideband microstrip-fed monopole antenna having frequency band-notch function", IEEE Microw. and Wireless Components Lett., vol. 15, issue 11, pp. $766-768$, Nov. 2005.

[6] Y. J. Cho, K. H. Kim, D. H. Choi, S. S. Lee, S.-O. Park, "A miniature UWB planar monopole antenna with $5-\mathrm{GHz}$ band-rejection filter and the time-domain characteristics", IEEE Trans. Antennas Propag., vol. 54, issue 5, pp. 1453-1460, May 2006.

[7] W. Choi, J. Jung, K. Chung, J. Choi, "Compact wideband printed monopole antenna with frequency band-stop characteristic" IEEE APS 2005 vol. 3 A, pp. 606-609, Jul. 2005.

[8] D.C. Thompson, O. Tantot, H. Jallageas, G.E. Ponchak, M.M. Tentzeris, J. Papapolymerou, "Characterization of liquid crystal polymer (LCP) material and transmission lines on LCP substrates from 30 to $110 \mathrm{GHz}$ ", IEEE Trans. on Microw. Theory Tech., vol.52, no.4 , pp. 1343-1352, Apr. 2004.

[9] Ansoft High Frequency Structure Simulator (HFSS). Ver. 9.2 Ansoft Corporation.

[10] S. Nikolaou, G. E. Ponchak, J. Papapolymerou, and M. M. Tentzeris, "Compact Ultra wide-band (UWB) CPW-fed elliptical monopole on liquid crystal polymer (LCP)", accepted for publication at IEEE APS 2006, Jul. 2006. 